$\begin{array}{r}\text { Volume and Issues Obtainable at Center for Sustainability Research and Consultancy } \\ \text { Journal of Business and Social Review in Emerging Economies } \\ \text { ISSN: 2519-089X (E): 2519-0326 } \\ \text { Volume 6: No. 4, December } 2020 \\ \text { JSRC } \\ \text { Journal homepage: www.publishing.globalcsrc.org/jbsee } \\ \hline\end{array}$

\title{
Pre and Post Covid-19 Lockdown: How the Aqi of Three Major Cities of Pakistan will Change?
}

\section{Ume Laila $^{1}$, Najma Sadiq ${ }^{2}$, Tahir Mehmood ${ }^{3}$, Tooba Rehan Haqqi ${ }^{4}$}

${ }^{1}$ Assistant Professor, Government \& Public Policy, School of Social Sciences and Humanities (S3H), National University of Sciences and Technology (NUST), H-12 Sector, Islamabad, Pakistan, dr.umelaila@s3h.nust.edu.pk

${ }^{2}$ Assistant Professor, Head of the Department, Department of Mass Communication, School of Social Sciences and Humanities (S3H), National University of Sciences and Technology (NUST), Islamabad, Pakistan, najmasadiq@gmail.com

${ }^{3}$ Assistant Professor, Department of Communication studies, BahaUddin Zakariya University, Multan, Pakistan, tahirmahmood@bzu.edu.pk

${ }^{4}$ Graduate Public Administration, Department of Government \& Public Policy, National University of Sciences and Technology (NUST), H-12 Sector, Islamabad, Pakistan, Tooba.bpa16s3h@s3h.nust.edu.pk

\begin{tabular}{l}
\hline ARTICLE DETAILS \\
\hline History \\
Revised format: November \\
2020 \\
Available Online: December \\
2020 \\
\hline Keywords \\
COVID-19 Lockdown, Air \\
Pollution, Air Quality Index, \\
Karachi AQI, Islamabad AQI, \\
Lahore AQI
\end{tabular}

JEL Classification

MO, M12

\begin{abstract}
Pakistan being in the list of developing countries has shown tremendous response towards the control of pandemic COVID-19. This paper evaluates the pre and post COVID 19 lockdown situation of air quality and provides an evidence of the air quality amid the lockdown and how it started to improve. The air quality indexes of three major cities of Pakistan i.e. Karachi, Islamabad and Lahore are compared, taking into account the indexes before and after the imposition of lockdown. The city wide presence of major pollutants like Sulphur Dioxide and Nitrogen Dioxide also reduced. The results show how taking serious measures can help in reducing the air pollution and help the environment to restore. Following analytical approach and situational analysis certain inferences have been drawn that the air quality index has worsen, and the atmospheric condition have turn out to be shoddier than the pre-pandemic situation. In the last section certain policy recommendations have been provided in order to maintain a healthy air quality.
\end{abstract}

(C) 2020 Center for Sustainability Research and Consultancy Pakistan under a Creative Commons Attribution-NonCommercial-ShareAlike 4.0

Corresponding author's email address: dr.umelaila@s3h.nust.edu.pk

Recommended citation: Laila., U., Sadiq, N., Mehmood, T. \& Haqqi, T. R. (2020). Police Brutality and Reforms in Pakistan. Journal of Business and Social Review in Emerging Economies, 6(4), 13791389

\section{Introduction}

The new year 2020 came along with Global Health Emergency due to the Covid-19 (coronavirus) pandemic. With the reckless spread of the virus, countries started to observe lockdowns, and obviously, 
Pakistan also had to do so. Starting from Karachi in late February the major cities like Islamabad, Lahore Peshawer, etc imposed curfews and lockdowns. With this decision, nearly all production houses were shut down, air transport was restricted, the commercial sector dumped, people started to work and school from home which meant no traffic on roads. The environmental revamping has become a byproduct of this pandemic and the major component of this is the improving air quality index of a country like Pakistan, the catalog of which had fallen to hazardous levels (Pakistan Air Quality Index and Air Pollution Information, 2020). The case of improvement is not only in Pakistan but all over the world. This study shall keep in focus the three main cities of Pakistan which happen to be the busiest and the most polluted cities of Pakistan. The research shall focus on the comparison of pre and post AQIs of the three cities.

\section{Literature Review}

Various authors have tried to investigate how lockdowns due to COVID have impacted the environmental conditions of either the specific area or the impact is worldwide. Saeida, Deepak and Mustansar have explained in their article, Environmental Perspective of COVID-19, that due to the reduced economic activities the condition of water and air is improving day by day. Quoting directly from the article, the authors have used the following words to explain the situation prevalent around the world "All over the world, flights have been canceled and transport systems have been closed. Overall, the economic activities have been stopped and stock markets dropped along with the falling carbon emission. However, the lockdown of the COVID-19 pandemic caused the air quality in many cities across the globe to improve and drop in water pollutions in some parts of the world" (Saeida, Deepak, \& Mustansar, 2020). Not only this Rui and Acheng in their article "Does Lockdown reduces Air Pollution?" have discussed the atmospheric condition of 44 cities in Northern China. They claim that due to the travel restrictions imposed the concentration of pollutant gases has declined by $24 \%$ (maximum). Apart from this other factor which proved beneficial for atmospheric restructuring include less human mobility and reduced consumption and production. After careful analysis, the study revealed that the Air Quality Index of Northern China decreased by $7.80 \%$ during the lockdown period (Rui \& Acheng, 2020) . In a separate article named "Air Quality Change In Seoul, South Korea Under Covid-19 Social Distancing: Focusing On PM2.5" by Beom-Soon Han and others, have augmented the reduction of PM2.5 particles and other air pollutants within 30-day time period. They have compared these results with that of 5-yreared data and concluded that social distancing has contributed in reducing the longrange pollutants transmission (Han, et al., 2020) . Chang and Gong have discussed the Air Quality variation in different regions. In the article " Air Quality Variation in Wuhan, Daegu, and Tokyo during the Explosive Outbreak of COVID-19 and Its Health Effects" have iterated the positive effects due to the pandemic. The have proclaimed that the air quality of these three places have improved by analyzing the health conditions of 10-year old children, which is evidential from the fact that the time period of allergic airway infection in children has increased, meaning now it takes a lot of time to reach to the acute level (Ma \& Kang, 2020). If at one point COVID 19 has had negative implications on the humanity it has for sure created some positive impacts for the mother nature. Considering the atmospheric conditions of India alone it has been observed that the atmosphere has revived due to the restricted human activities and reduced emissions (1Shubham, Jingsi, Hongliang, \& Sri, August 2020) (Jain \& Tanya, 2020) (Kumari, 2020). European countries began to monitor the NOx composition over the region and found out vast difference of concentration of nitrogen oxides in atmosphere during lockdown and without lockdown (Menut, Bessagnet, \& Siour, Nov 2020). Similarly, Spain and Barcelona carried out the largest experiment of time during the covid lockdown and experienced $75 \%$ reduction of pollutants in the environment which resultantly has improved the AQI of the two cities (Baldasano, Nov 2020).

\section{Methods}

\subsection{Location Description}

Islamabad is the capital of Pakistan and is the federally administrated capital. It is the 9th largest city and has a population of around 3.1 million. It covers an area of $906.5 \mathrm{~km} 2$ and has a humid subtropical 
climate with five seasons and heavy rainfalls. Islamabad is the port for immense air traffic and normal road traffic (Pak, 2017).

Karachi the largest city of Pakistan is the capital of Sindh province. It is a cosmopolitan city covering an area of $3780 \mathrm{~km} 2$ and has a total of 1.4 million population. It is the coastline of Pakistan and has hot desert climate and receives little to no rainfall. The Jinnah Intl. Airport Karachi is the busiest airport and receives a total of 7.2 million passengers. same is the situation of the road network, where thousands of vehicles remain on the road and thus creating traffic problems (Gov, 2016).

Lastly, Lahore, the Metropolitan city of Pakistan is the capital of Punjab province and is the 2nd largest city after Karachi. Lahore covers an area of $1772 \mathrm{~km} 2$ with 1.1 million population and has a semi-arid climate with heavy rainfalls and thunderstorms. the city of Lahore receives average rate of air and road transport, and is a home for most of the VIP flights (GOV, 2014).

\section{Results and Discussion}

\subsection{Pre Covid Air Quality Index}

Air Quality Index tells the number of intoxicants present in the air and how to fit or unfit is the air to breathe. According to WHO, nearly 4.2 million people around the globe lose their lives due to inhalation of unhealthy air and in the past 1 year Pakistan has recorded 2000 deaths due to lungs disease which the people contracted by inhaling unhealthy air (Global Health Observatory Data, 2020). Talking about the situation of Air Quality Index December 2019 (US Consulate Air Pollution Pakistan, 2019-2020) of three major cities of Pakistan i.e. Islamabad, Karachi, and Lahore, when every sector was working at an optimal level the maximum and minimum levels of Air Quality Index were as follows:

\begin{tabular}{|l|l|l|l|}
\hline CITY & Islamabad & Lahore & Karachi \\
\hline MINIMUM INDEX & 78 & 171 & 102 \\
& MODERATE LEVEL & UNHEALTHY LEVEL & UNHEALTHY LEVEL \\
\hline MAXIMUM INDEX & 213 & 478 & 210 \\
& VERY UNHEALTHY & HAZARDOUS LEVEL & $\begin{array}{l}\text { VERY UNHEALTHY } \\
\text { LEVEL }\end{array}$ \\
\hline
\end{tabular}

Table 1: Air Quality Index of Islamabad, Lahore, Karachi December 2019 (Source: Real-Time Air Quality Index)

The above table clearly shows how bad was the air condition in December 2019, the index reaching the hazardous levels. But the situation did begin to improve after the lockdown was imposed. The indexes dropped drastically, and the Quality of Air began to improve. The level of air pollutants in the atmosphere began to decline as no more factories were emitting hazardous SO2, neither the aircraft and vehicles were combusting their fuels and producing NO2 and other sources of carbon footprints were minimized. This improvement was traced by the real-time satellites. According to the Real-Time Index, the air quality of the cities Islamabad, Lahore, and Karachi has improved in April and May, when the lockdown was at the peak point. For simplicity of this graph maximum values of PM 2.5 have been taken, which reveals a sharp improvement in the air Quality Index. Furthermore, it should be noted that before the lockdown, the unhealthy levels of Air Quality used to remain for 10to15 days but after the imposition of the lockdown the maximum level reached was only for one day (US Consulate Air Pollution Pakistan, 2019-2020). 


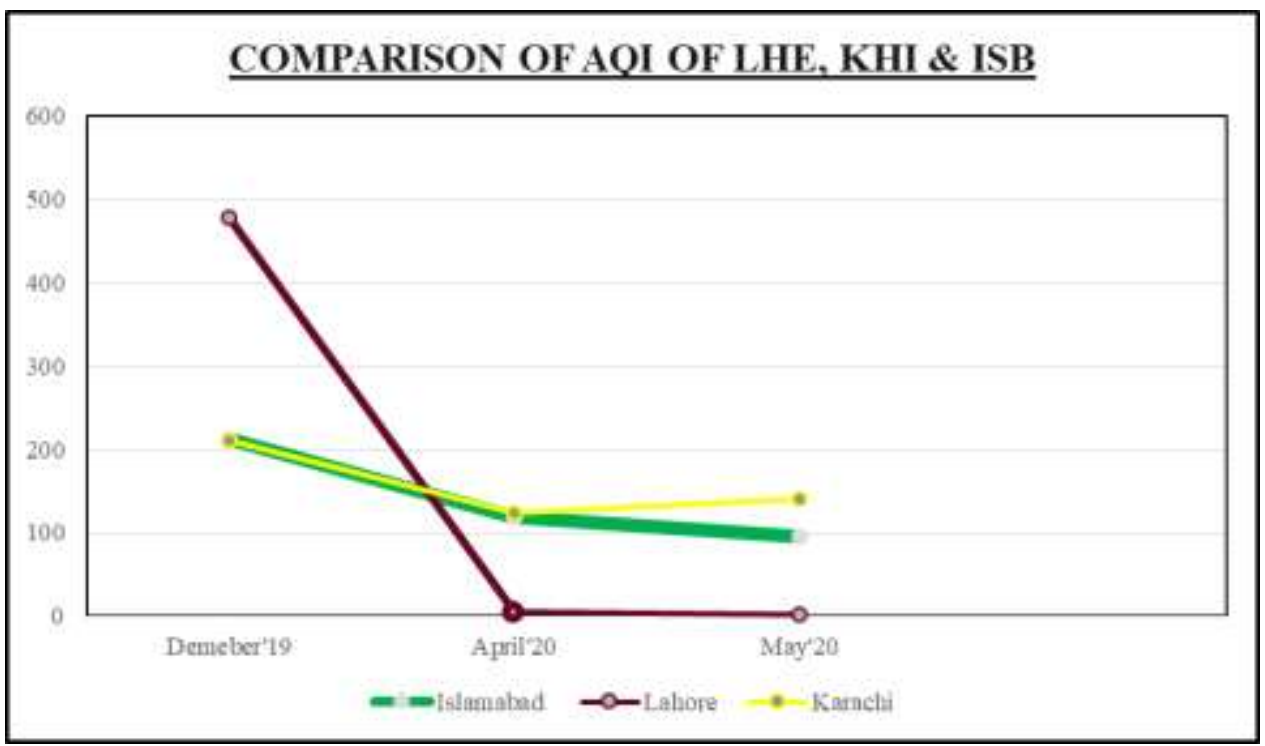

Figure: Graphical representation of the Air Quality Index (PM 2.5) Of Islamabad, Lahore, Karachi, 2019-20. (Source: Real-Time Air Quality Index)

\subsection{Post Lockdown Air Quality Conditions}

Despite this revamping, the real question comes "will the situation be the same after the lockdown is hauled up?" the answer is NO. There are numerous reasons behind this answer which shall be discussed in detail. Firstly, after calling off this lockdown, the production houses will resume their work. By production house, it means all sorts of factories from textiles to steel mills to brick kilns every workshop. This is fine because economic activity must resume now and then, but the thing which is alarming for us is the factories that will be operating and producing commodities at a faster rate. More production means more combustion of fuel to run the machines and thus increased the dumping of wastes and by-products. Not only that, recently the factories are working day and night to meet the loss incurred by them from February till May which means extra power consumption and hence again a shortage of electricity. The shortage of electricity in Pakistan is a different subject hence keeping it aside, but the main problem which needs not to be ignored is the pollutants released in the atmosphere by the factories.

\subsection{Increased SOx Presence in Atmosphere}

The textile industry in Pakistan has resumed its production. To meet the online orders and other demands in the market, the factories are functioning for up to 14 hours thus emitting dangerous chemicals into the air. The major proportion is of Sulphur Dioxide, other toxins include Nitrogen Dioxide and Suspended Particulate Matter (SPM) ( Various Pollutants Released into Environment by Textile Industry, 2012). These pollutants are the major reason that spikes the air pollution. The enhanced proportion of Sulphur dioxide does not only decline the quality of air index but also imposes the threat on the people prone to asthma and other diseases related to the lungs. This situation is witnessed in China too after the lockdown was lifted and the economic activity was resumed. Through the following picture, captured from NASA's official website, the SO2 presence over China's North region shows the emission due to resumed factory production. The three pictures below demonstrate three different days and similarly three different cases of SO2 presence over the Pakistani Region. It should be kept in mind that the complete lockdown was only called off in the region of Islamabad and Lahore but not in Karachi. The first picture illustrates blue covering which is the minimum level of SO2 presence in the atmosphere (Atmospheric Composition of Sulphur Dioxide , 2020). This is the accepted levels of Sulphur Pollutant which at minimum effects the Air Quality Index. But the situation started to deteriorate once the factories started operating and the color suddenly changes from blue to green. Although up till green the Sulphur presence in the atmosphere is deemed not to be dangerous the inference here which can be drawn is that within 10 days the concentration is increasing radically hence 
I assume that within a month or so the Sulphur concentration will again reach the hazardous concentration that is 3.85 Column Mass and above; this concentration of Sulphur has been reached by China. The Centre for Research on Energy and Clean Air (CREA) in China has published a report showing a sharp increase in the SO2 presence over the region where the factories are operational. CREA claims that by comparing the accumulation of SO2 in May-June 2019 and May-June 2020 revealed that the levels have exceeded the pre-pandemic era. CREA now fears that if some controlling policies are not implemented the situation might go worse which may prove to be alarming for the people living in there (Lauri, 2020).

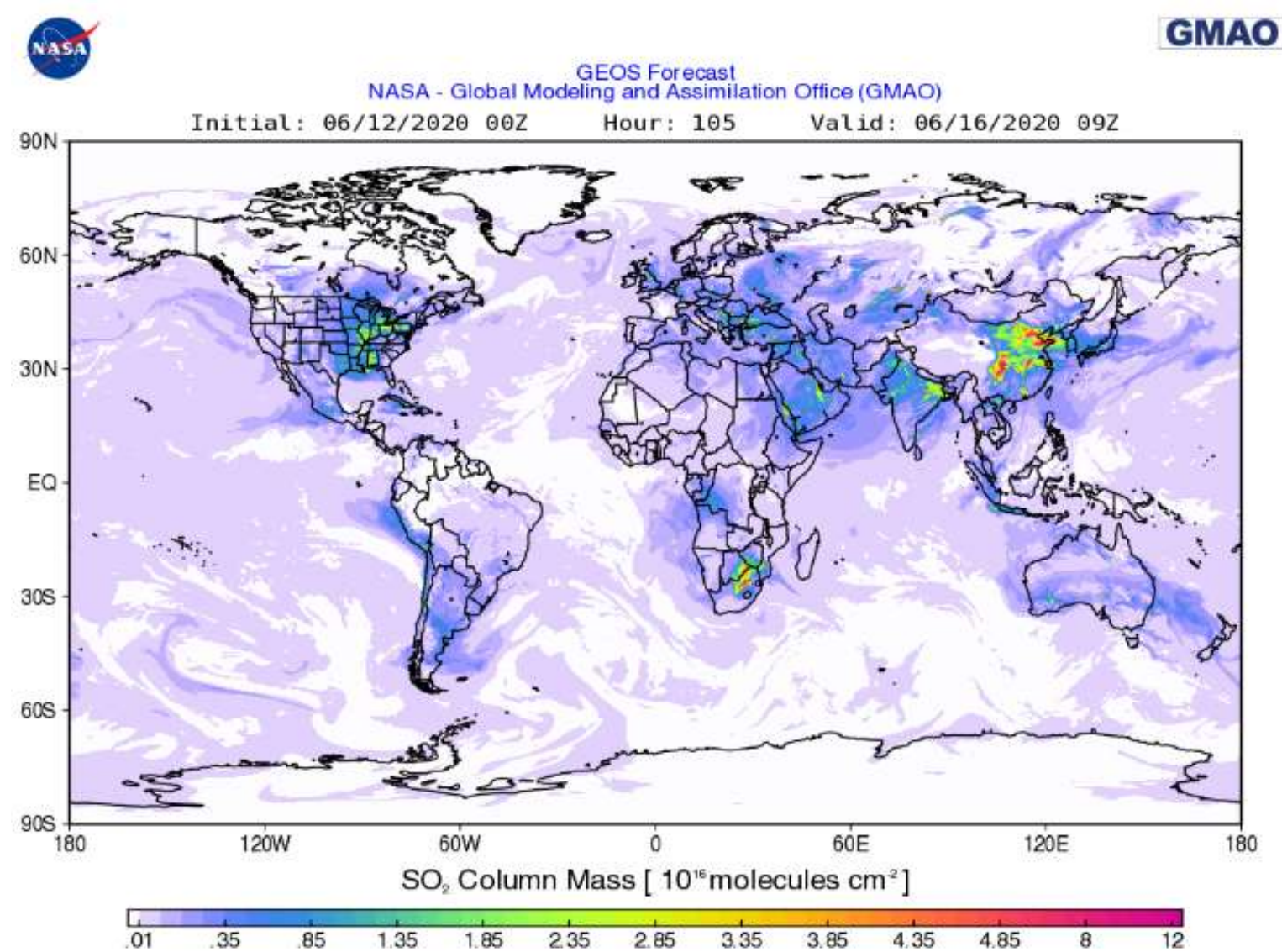



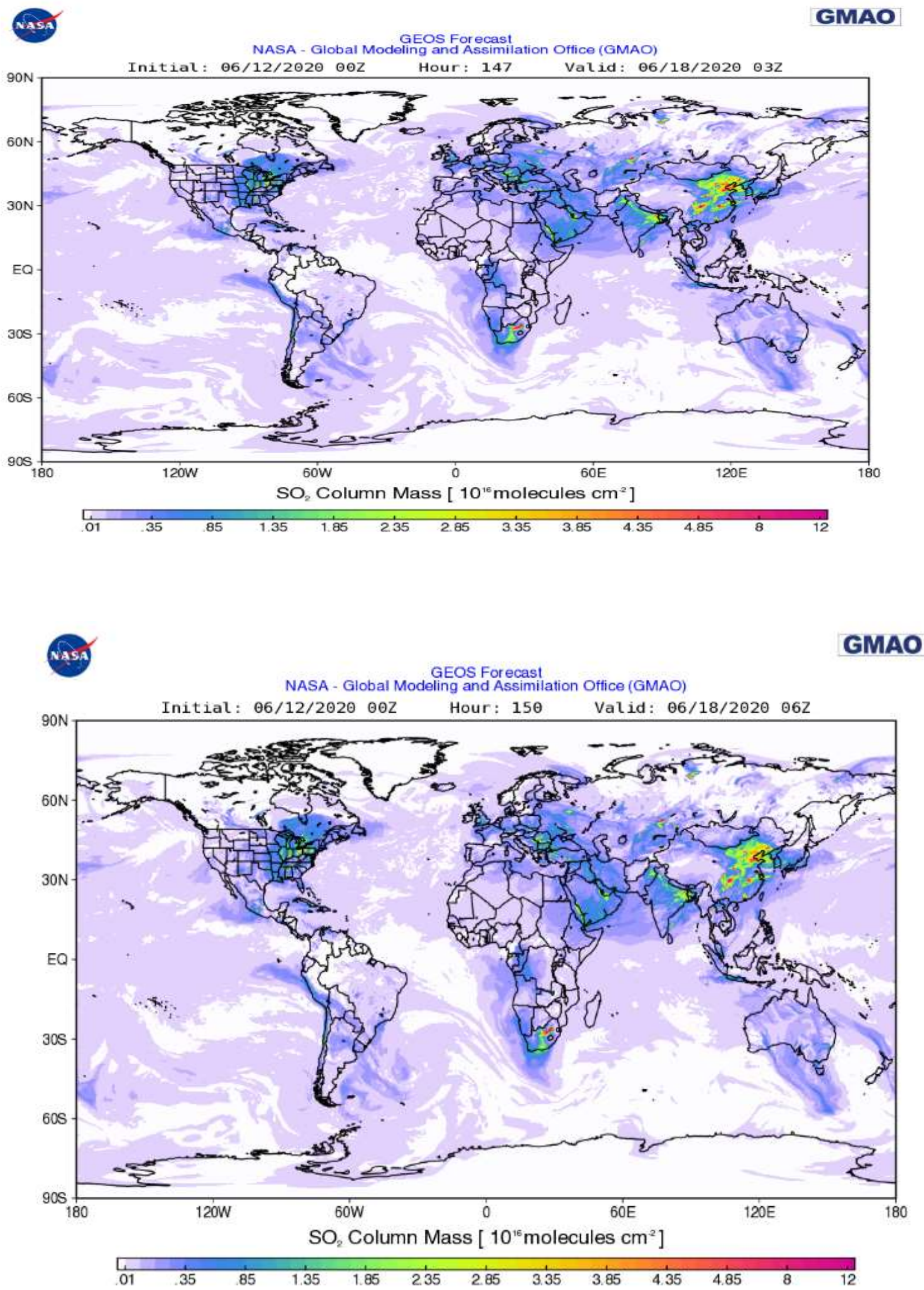

Figure: Global SO2 presence in the atmosphere (Source: Global Modeling and Assimilation Office NASA) 


\subsection{Increased NOx Presence in Atmosphere}

The Prime Minister of Pakistan has issued a notice to lift all air travel restrictions by June 15th, which means that from then onwards all the airlines will be operating their respective flights and not only the national flag carrier. Like other industries, the airline industry is the most affected one and has seen a major financial setback. After the restrictions are called off, airlines will be operating many flights to fill the fiscal deficit. Not only that people stranded all over Pakistan especially shall continue their travel. Aircraft emit various pollutants due to the combustion of various fuels and mainly diesel. This combustion releases toxic pollutants which include Carbon Dioxide, Oxides of Sulphur, Oxides of Nitrogen, unburnt Hydrocarbons, Carbon Monoxide, and Particulate Matter (European Aviation Environmental Report, 2017) . Carbon Dioxide and Oxides of Nitrogen are the two pollutants that form the major proportion of emission by combustion. But the recent studies reveal that percentage of Nitrogen Oxides emitted by aircraft in the atmosphere is increasing incredibly as compared to Carbon Dioxide. For the past three months from 23rd March 2020 till 15th June 2020, all the domestic flights were canceled, only the chartered international flights were being operated by Pakistan International Airline and all other airlines were shut down. In this period at most 35 flights had been operated, which is only 10 percent of the flights which come in and out of Pakistan in a day. It should be noted that in this period the levels of Nitrogen Oxide had been reduced as revealed by the satellites of NASA, but once all airliners are operating the situation won't be the same. The levels of Nitrogen Oxide will increase sharply and thus the Air Quality Index of each city might face an alarming situation.

But this pollutant is not only restricted to the aircraft or jetliners. It is also released by the combustion in vehicles. After the lockdown is elevated, all business activities and corporate sector will resume working. Since 26th February in Karachi and from 13Th March 2020 in Islamabad and Lahore, everyone was working from home and people were going out only to buy necessities. Least intercity travels had been observed with many people quarantining themselves at home. But once the offices reopen and the corporate sector continues its working, people will have to rejoin their offices. Not only that, due to the fear of contagion pandemic virus, but many people will also avoid using public transport and will surely be using their private conveyance. Which means more vehicles on the road with more traffic jams. This is what Kate Abnett has discussed in her article regarding the situation of pollutants in China after the lockdown is called off. She says that the concentration of some pollutants has risen way above what China had in the same days last year. She says that the situation of air quality in China began to worsen when the people started to drive their private cars to work instead of using the monorails and other public transport. The traffic jams in densely populated areas are causing threats and reports claim that over 1500 people are vulnerable to death due to the inhalation of intoxicants mainly nitrogen oxides (Kay, 2020).

Moreover, the satellites of NASA have revealed a sweeping of NO2 present in the troposphere above Pakistan. The environmentalists of NASA claim that this reduction in the pollutants is merely due to the reduced use of aerosols, and combustible liquids (Global Nitrogen Dioxide Monitoring, Pakistan, 2020) . But the following figures retrieved from NASA's official websites explain the situation of Nitrogen Dioxide present in the troposphere of 3 major cities. The graphs present below each satellite image shows the increasing trend on Nitrogen Oxides in the atmosphere post-travel (both air and ground) restrictions are lifted, for the ease of understanding and purpose of comparison, the time between April and June has been highlighted. 

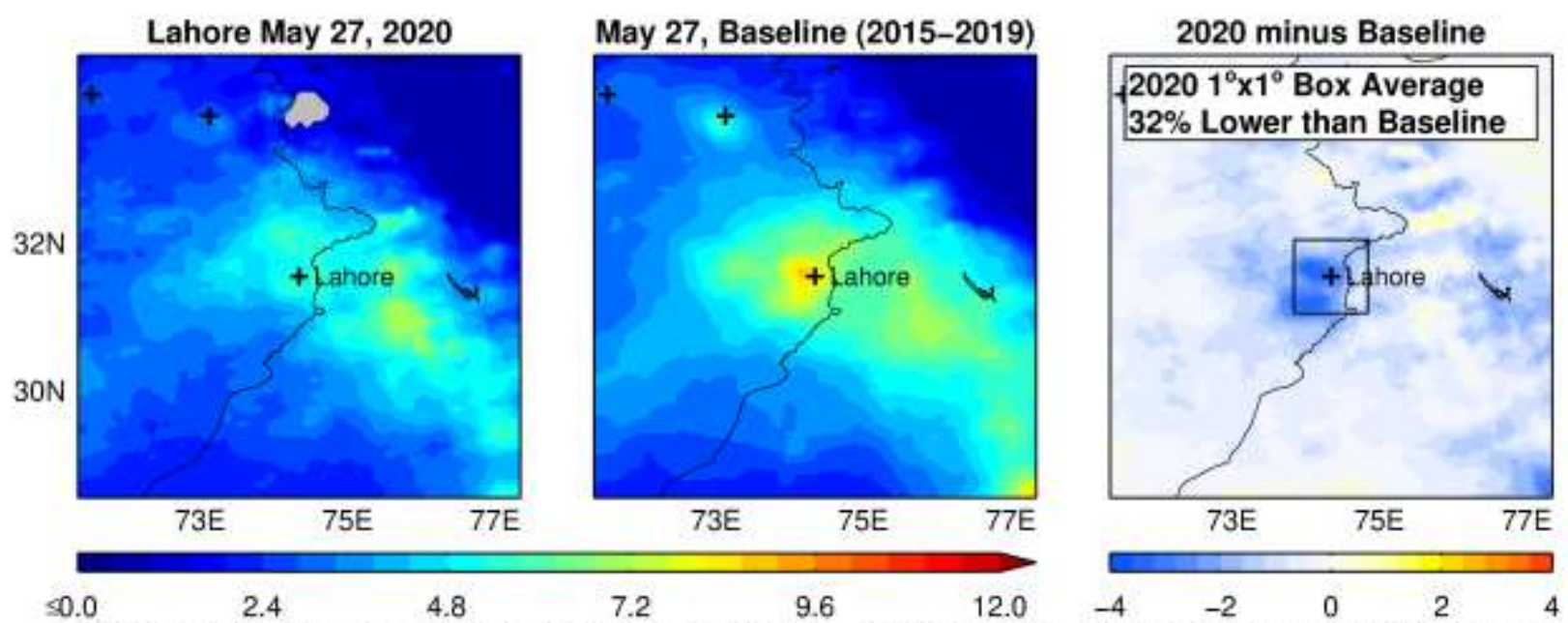

Aura/OMI 15 Day Running Mean $\mathrm{NO}_{2}$ Column $\left[10^{15}\right.$ molecules $\left.\mathrm{cm}^{-2}\right]$ (Gray: No Data) NO $\mathrm{N}_{2}$ Column Difference $\left[10^{15} \mathrm{molec}^{-2} \mathrm{~cm}^{-2}\right]$ Image Credit: NASA

Figure: Satellite Capture of NOx Presence Over Lahore City (Source: NASA)

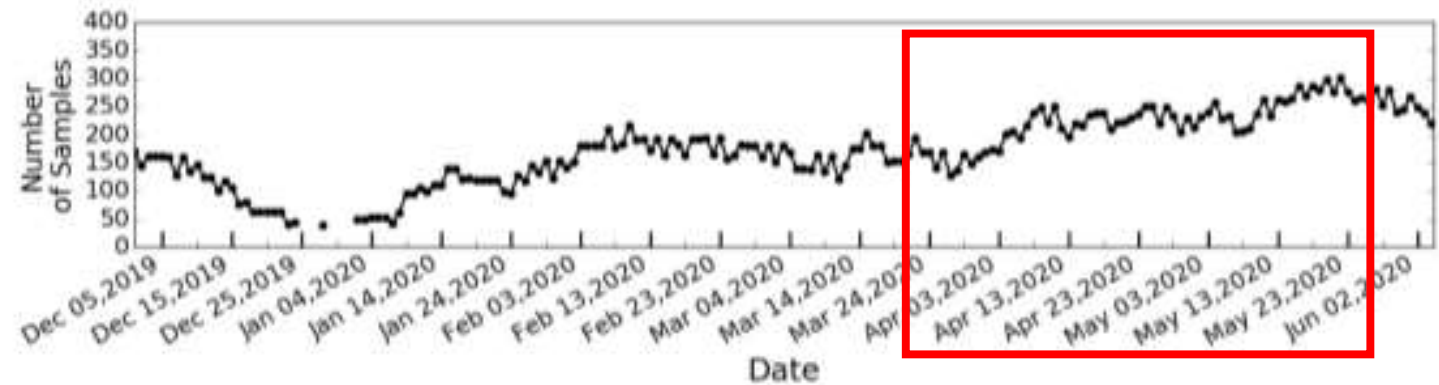

Image Credit: NASA

Figure: Graph of NOx Emissions in Lahore City (Source NASA)
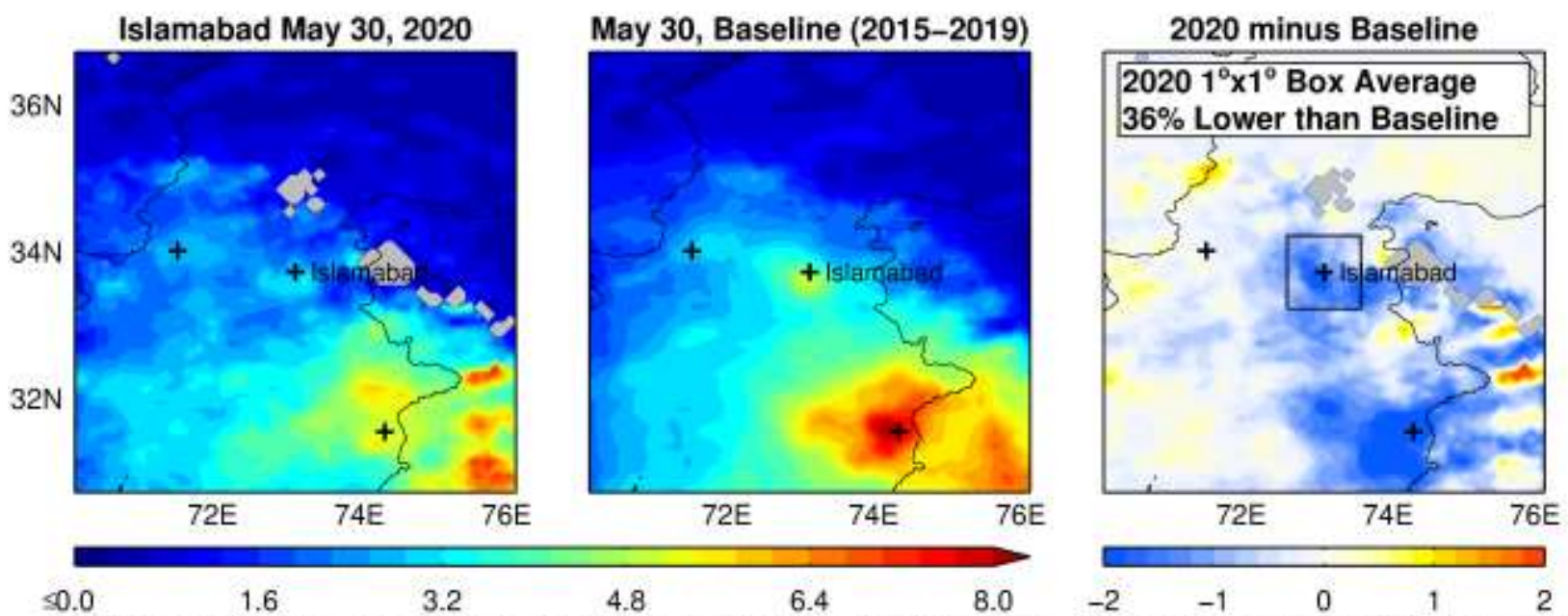

Aura/OMI 15 Day Running Mean $\mathrm{NO}_{2}$ Column [ $10^{15}$ molecules $\left.\mathrm{cm}^{-2}\right]$ (Gray: No Data) NO Column Difference [10 $\left.{ }^{15} \mathrm{molec}_{2} \mathrm{~cm}^{-2}\right]$ Image Credit: NASA

Figure: Satellite Capture of NOx Presence Over Islamabad City (Source: NASA)

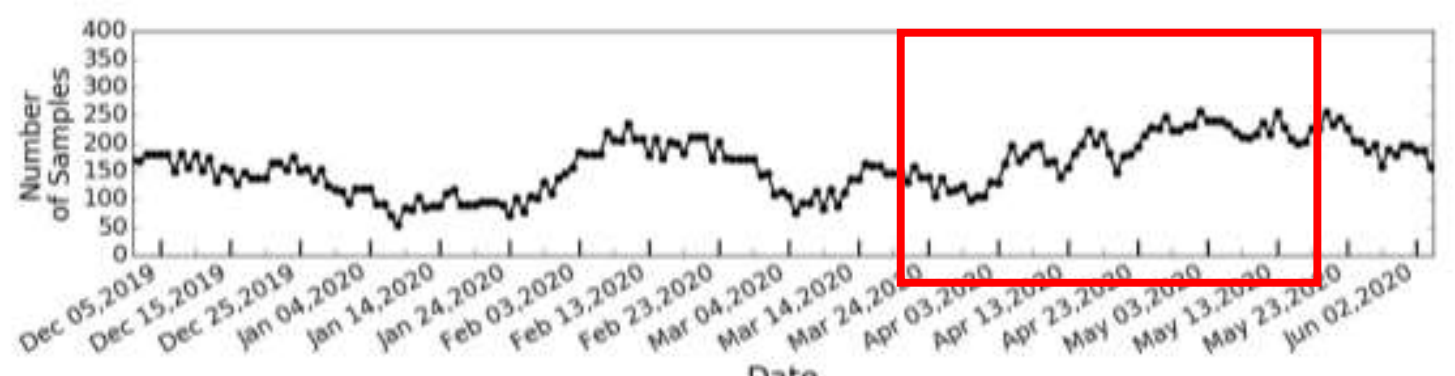

Date

Image Credit: NASA 
Figure: Graph of NOx Emissions in Islamabad City (Source NASA)
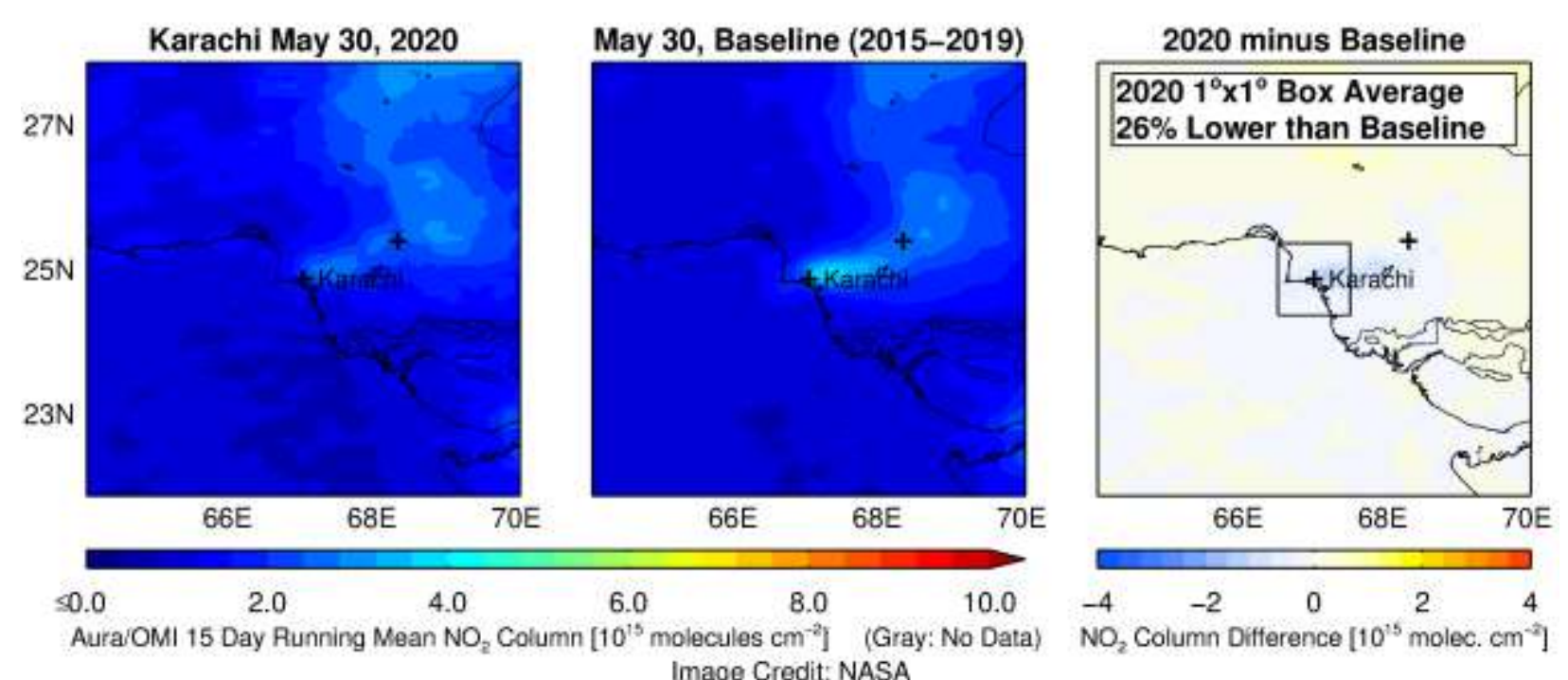
Image Credit: NASA

Figure: Satellite Capture of NOx Presence Over Karachi City (Source: NASA)

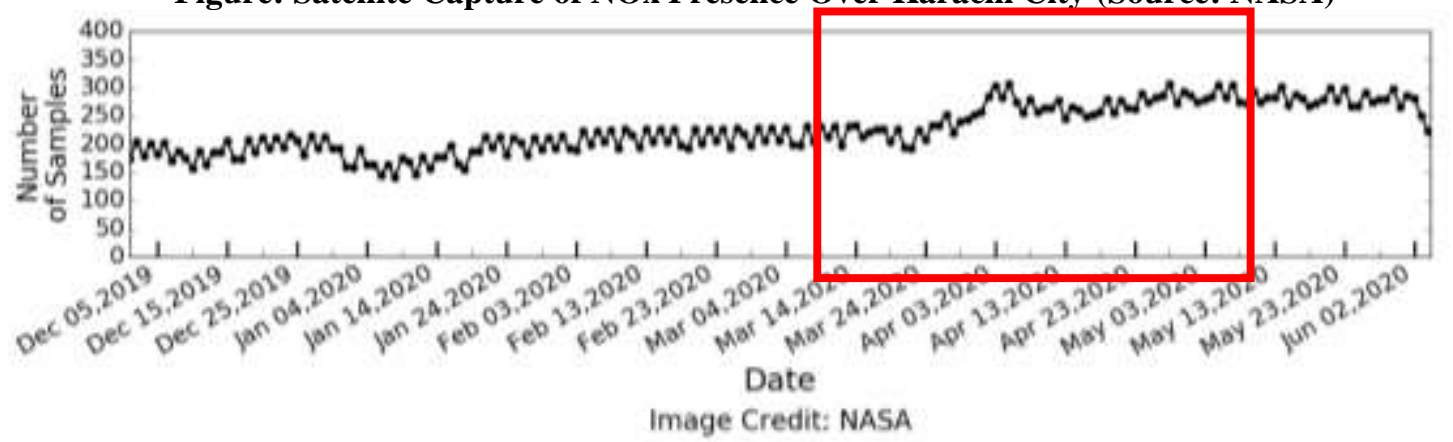

Figure: Graph of NOx Emissions in Karachi City (Source NASA)

On comparing the NOx condition of all the three cities, it is evidential that due to lifting of lockdown and allowing air travel to and from Lahore and Islamabad the emissions have an increasing trend, whereas by looking into the case of Karachi the emissions are at a constant rate as the smart lockdown is still in place.

\section{CONCLUSION}

These arguments are only valid to the point if no radical step is either taken by the relevant authorities or the individuals themselves. It should also be noted that these are mere projections based on the past track record of what the air quality was in Pakistan and a collar drawn while considering the post-lockdown atmospheric situation in China. But nothing is impossible in this world. Pakistan has a lot more potential than other countries to make it a better place to live and a region having a healthy atmospheric condition. For this, the environmental agencies along with the relevant ministry must work hard and draw certain policies that shall prove beneficial for the country and our future generations. Certain policy recommendations are given below:

\section{Policy\#1:_All Commercial Activities to Be Restricted Between 9 Am. To 5 Pm.}

If the government restricts all the commercial activities (including malls and other shopping arcades) between 0900-1700 hrs, this will be beneficial for Pakistan not only in the environmental aspect but economically also. By restricting the activities in these hours, the energy consumption will be least as daylight illuminates and reduces the need for electricity to 10-20\%, in return Pakistan shall not be facing any sorts of "Electricity Shortfalls". Not only that the traffic jams in the peak hours can be avoided as the traffic shall be evenly distributed all over the day. 


\section{Policy\#2: Controlling the Air Traffic}

The air traffic should be restricted. This can be done by limiting the number of international flights landing in and taking off from all over Pakistan in a day. For instance, if 100 aircraft of international airlines land here in Pakistan, reduce the traffic by permitting let's say only 50 flights in a day. This will not only be helpful for the domestic airlines as they will get a chance to operate flights but will also reduce the combustion emissions from the aircraft.

\section{Policy\#4: Turning Towards Renewable Energy}

Finally, is moving towards renewable energy, moreover solar energy. Pakistan has the potential of producing 100,000 MW of electricity from solar energy. Islamabad is in the province of Punjab where it experiences about $5.0-5.5 \mathrm{kWh} / \mathrm{m} 2 /$ day of normal solar radiations that are considered best rays to operate solar cells. If in Islamabad alone solar panels are installed it can operate about 500,000 streetlights of $400 \mathrm{MW}$ which can replace the sodium lights mounted. Apart from this many small localities that are far from the national grid can be facilitated by solar energy. According to a given estimate, if solar panels are installed in the outskirts of Islamabad, they can lighten up to 40,000 villages 24/7 that are not provided with electricity even for about 10 hours in a day (Intikhab, F, F, \& Fayyaz, December 2012). Pakistan has a capacity to fight against any difficult situation. If proper remedies are taken the good air quality can be maintained even after all economic activities are resumed. As this paper has taken a situational approach thing might turn out to be different than the analysis but still in order to provide a habitable place for the future generation certain remedial actions must be taken by the government and by the individuals themselves.

\section{References}

Various Pollutants Released into Environment by Textile Industry. (2012, May). Retrieved from Fibre 2 Fashion: https://www.fibre2fashion.com/industry-article/6262/various-pollutants-released-intoenvironment-by-textile-industry.

Atmospheric Composition of Sulphur Dioxide . (2020, May-June 30th-12th). Retrieved from Global

Modelling and Assimilation Office, NASA : https://fluid.nccs.nasa.gov

Baldasano, J. M. (Nov 2020). COVID-19 lockdown effects on air quality by NO2 in the cities of

Barcelona and Madrid (Spain). Science of Total Environment .

European Aviation Environmental Report. (2017). Retrieved from European Union Aviation Safety

Agency: https://www.easa.europa.eu/eaer/topics/overview-aviation-sector

Global Health Observatory Data. (2020). Retrieved from World Health Organization :

https://www.who.int/gho/phe/outdoor_air_pollution/burden/en/

Global Nitrogen Dioxide Monitoring, Pakistan. (2020). Retrieved from National Aeronautics and Space

Administration: https://so2.gsfc.nasa.gov/no2/no2_index.html

GOV, P. (2014). Facts anf Figures- Lahore. Retrieved from Lahore Development Authority :

https://www.lda.gop.pk/

Gov, P. (2016). Facts and Figures- Karachi. Retrieved from Karachi Development Authority: http://www.kda.gos.pk/Contents.aspx?id=103

Grace. (2020, may ). CBS Interactive Inc. Retrieved from CBS News : https://www.cbsnews.com/news

Han, B.-S., Park, K., Kwak, K.-H., Park, S.-B., Jin, H.-G., Moon, S., . . Baik, J.-J. (2020). Air Quality

Change in Seoul, South Korea under COVID-19 Social Distancing: Focusing on PM2.5.

International Journal on Environmental Health and Public Research .

Intikhab, U., F, A. A., F, K., \& Fayyaz, A. (December 2012). Estimation of Solar Energy Potential for Islamabad, Pakistan. Research Gate .

Jain, S., \& Tanya, S. (2020). Social and Travel Lockdown Impact Considering Coronavirus Disease (COVID-19) on Air Quality in Megacities of India: Present Benefits, Future Challenges and Way ForwardJi. Special Edition: Aerodol Air QUality, 1222-1236. 
Kay, A. (2020, may 18 ). Reuters Environment. Retrieved from Reuters : https://www.reuters.com/article

Kumari, P. (2020). Impact of lockdown measures during COVID-19 on air quality- A case study of India. International Journal of Environmental Health Research .

Lauri, M. (2020). China's air pollution overshoots pre-crisis levels for the first time. Centre for Research on Energy and Clean Air.

1Shubham, S., Jingsi, G., Hongliang, Z., \& Sri, H. (August 2020). Effect of restricted emissions during COVID-19 on air quality in India. Science of the total environment.

Ma, C.-J., \& Kang, G. (2020). Air Quality Variation in Wuhan, Daegu, and Tokyo during the Explosive Outbreak of COVID-19 and Its Health Effects. International Journal on Evironment Research and public Health.

Menut, L., Bessagnet, B., \& Siour, G. (Nov 2020). Impact of lockdown measures to combat Covid-19 on air quality over western Europe. Science of the Total Environment .

Pak, G. (2017). Facts And Statistics Islamabad. Retrieved from Capital Development AuthorityIslamabad: http://www.cda.gov.pk/about_islamabad/vitalstats.asp

Pakistan Air Quality Index and Air Pollution Information. (2020). Retrieved from Empowering the World to breath clean air- IQAir: https://www.iqair.com/pakistan

PAQIM. (2019-2020, December-May). Islamabad US embassy: Real-Time AQI. Retrieved from Real Time Air Quality Index Pakistan: https://aqicn.org/city/pakistan/Islamabad/us-embassy/

PAQMI. (2019-2020, December-May ). US Embassy Karachi Real Time AQI. Retrieved from Pakistan Real Time Air Quality Index : https://aqicn.org/city/pakistan/Karachi/us-embassy/

PAQMI. (2019-2020, December-May). US Embassy Lahore Real Time AQI. Retrieved from Pakistan Real Time Air Quality Index : https://aqicn.org/city/pakistan/Lahore/us-embassy/

Rui, B., \& Acheng, Z. (2020). Does lockdown reduce air pollution? . ELsevier; Science DIrect.

Saeida, S., Deepak, R., \& Mustansar, H. (2020). Environmental Perspective of COVID-19 . Elsevier, Science Direct .

US Consulate Air Pollution Pakistan. (2019-2020, December-May). Retrieved from Real Time Air Quality Index: https://aqicn.org 